quasi-voluntary, were correctly given. In such cases, both the ideas and the words representing them would present themselves before the mind, and fall into their proper places, almost, if not quite, without any voluntary effort."

There was abundant proof that, at least, simple ideas were clearly presented to her mind. She looked intelligent, assented and dissented promptly and correctly, and conducted herself quite sensibly and with perfect propriety. It did not appear how far she was able to conduct any more intricate process of thought; but it was stated by her friends, and afterwards positively confirned by herself, that she could not read to herself; which agrees with the imperfect use she was able to make of external symbols, in the shape of written or spoken words.

There was, however, no question about the presence of serious derangement in her power of employing the symbols expressive of ideas. Apprehension, or, to quote the words of Dr. Moxon, "in-coming language", was little affected; the fault lay chietly in the other term, the "out-going language", or expression; thus illustrating, as Dr. Moxon has noticed, the perfect distinctness of these "two departments of the mind's relation to language". Want of power to co-ordinate ideas (incoherence), though quite distinct from mal-coordination of words, the signs of ideas, may co-erist with it, as occurred in a lady whom I attended, in whom each of three epileptic fits was followed by delirium, and, as that sub. sided, by incoherence in the sclection and allocation of words. It was difficult to say, but I suspected that the incoherence in talk did not occur in this lady until the incoherence in thinking had passed away; as in the case of emotion, the delirium took the place of the will in arranging the patient's utterance.

My present patient, however, was little able to coordinate the arrangement of her words, and little more capable of adjusting the action of her muscles 80 as to pronounce intelligibly. Any sentence requiring voluntary effort to arrange its component parts speedily became a mere confusion of sounds, in which even words were not articulate. To the same cause was to be ascribed her very imperfect power of copying the utterance of another person. She could not thus copy the pronunciation of her own name; and she failed in repeating after me the simplest sentence, unless dissected word by word ; often isolated words were unattainable. Nor had she any greater ability to copy written words. It has to be added, however, that occasionally her imitations of articulated sounds had some phonetic resemblance to the original; as "nors", "funday", "see", "moom", for years, Sunday, three, more, respectively.

This imperfection in voluntary control became greatly exaggerated by the slightest emotion or hurry, even by the vexation of a failure; so that it was rarely that she could convey any information comprising more than one or two simple ideas.

But once more there was very manifest failure in recollecting words; and this was at the foundation of her trouble to quite as great an extent as loss of coordinating power. Thus she never recollected her surname; once even she substituted her maiden name; although she was quite ready with her Chris-

\footnotetext{
* A soinewhat parallel case is mentioned by Van der Kolk. A patient, who had lost the faculty of expression, could yet add up figures; and the combined effect of memory and of habitual connection of words was strikingly exhibited in a patient of my father's, who, having become aphemic, after abnormal roental labour in cataloguing a large manufacturing property, used the words "list complete". to exprese every idea, and to answer every question. The late Daniel U'Connell gave a good illustration of the distiuction which subsists between emotional utterances and intellectua expressions, when he silenced a Billingsgate fisherwoman merely by flinging at her technical terms taken from the books of Euclid. He narrated the inoident to a friend of my own.
}

tian name." Nor could she give me at any time the names of her children, of her family, the town in which she lived, etc.

This defect became especially apparent in questions involving numbers; e. g., her age, that of her child, the length of her illness, the date of her husband's death. It was singular that, in replying as to the length of her iilness, she uniformly (on several occasions) substituted "years" for "weeks"; and that, when corrected, she nevertheless made the same error immediately afterwards. On many occan sions, however, she was sensible of her mistakes, and would set herself right by counting on her fingers; proving that it was the symbol, and not the conception of the number, which was wanting.

As regards the other nervous symptoms in the case, it is only necessary to add, that sensation was very slightly impaired in the paralysed arm; that the functions of the various cerebral nerves were performed naturally; and that hearing, smell, and taste were intact. The patient continued under observation for eleven woeks; she made some advance towards recovery; but her progress was not very satisfactory.

In conclusion, I would specially refer to a valuable paper by Dr. Jackson in the Medical Times and Gazette, June 23rd, in which some most important suggestions are made for associating the various forms of functional derangement noticed in the preceding description by one link of connexion-viz., suspension of voluntary regulation of muscular action; and thus the subject is brought into immediate connexion with the study of the phenomena of chorea. The more the two diseases are compared, the nearer will bo the parallelism observed between them, and the clearer the light which each one casts upon the other.

\section{Briginal Commanxatixom.}

\section{ON PROGNOSIS IN HEART-DISEASE.}

By W. H. Broddrent, M.D., Assistant-Physician to St. Mary's and the Fever Hospitals; Lecturer on Physiology at St. Mary's Hospital Medical School.

\section{[Concluded from page 21\%.]}

UP to this point, I have been chiefly occupied in considering the organic and functional condition of the heart, and the effects of the changes which may have taken place in it on the systemic and pulmonary circulation; but there are other conditions not necessarily flowing from the heart-disease, which have a most important influence on the future of the patient. Among the most serious of these, is any tendency to anæmia, whether this is a consequence of the failing circulation, or induced by other circumstances. When the blood is poor, the walls of the heart are ill nourished, less competent to cope with any mechanical difficulty, less able to resist any dilating causes. There is also a liability to palpitation, which is injurious and dangerous in heart-disease, and an increased tendency to dropsy.

Again, in all cases, the position in life of the sufferer, and his habits, form a most important pro. gnostic element. In violent efforts, or in sustained exertion, there is a great strain upon the valves of the heart; and vicissitudes of temperature tax its powers of accommodation to different conditions of

- A similar instance is afforded in a very iuteresting case read by Dr.Sanders of Edinburgh, before the Medico-Chirurgieal Society of that city. 
tho circulation; while unfarourable hygienic influences tend to innutrition and degeneration. 'The man, therefore, who must labour with his hands, who is exposed to all weathers, whose food is otten of inferior quality and sometimes insufficient in quantity, who breathes impure air and indulges perhaps in strong drink, who seeks adrice only when he can no longer toil, and abandons all precautions as soon as he ceases to attend the hospital, has far smaller chances of long life than the man who can seek advice early, and who has adequate means to follow it out. In no cases, howerer, is the nimia cura medici more fital. The patient should be encouraged to take a hopeful riew of his condition, and permitted, and even urged, to work up to his strength.

A consideration of prognosis in heart-disease would be imperfect without reference to the modes of death; and, in connection with this part of my subject, I shall speak briefly of the symptoms which are the precursors of a fatal termination.

The immediate cause of death may be asthenia, pulmonary complications, or dropsy. I might mention, also, cerebral hæmorrhage, or softening, or embolism of the cerebral arteries; but, except the lastmentioned, these are in no way proper to heart-disease, and occur so often independently of it, that it is open to question whether they are not rather coincidences than consequences.

First, as to sudden death by syncope. I think I am not wrong in stating that, with the profession as with the public, it is very commonly believed that this is a contingency to which every sufferer from heart-disease is liable. 'This is indeed positively asserted by Dr. Fuller in the following passage, which closes his résume of the prognosis of valvular disease of the heart (p. 120): "In any and all cases life is apt to be arrested suddenly by syncope"-an assertion repeated almost word for word by $\mathrm{Dr}$. Aitken in his work on Medicine.

Is this so? My attention was first specially drawn to the question of prognosis in heart-disease by the discrepancy on this point between my experience and iny preconceived opinion. I had watched very many crses of ralvular disease of the heart without seeing this termination. In the post morten examinations I had made in cases of sudden death, $I$ had met with fitty degeneration of the heart in two, rupture of the left ventricle in two, aneurism of the left ventricle, adherent pericardinm, ossification of the coronary arteries (with angina pectoris), plugging of these vessels by ulceration in the aorta, primary malignant disease in the walls of the heart, and but two instances of valvnlar disease, in one of which the heart was fatty. It became evident that either my opinion was wrong, or my experience singular. I found, however, that Dr. Stokes and Dr. Walshe had long since arrived at the conclusion to which my observation seemed to point. Dr. Stokes states that sudden death in diseases of the heart is by no means so frequent as is generally supposed, and that it bappens principally in examples of solution of continuity; and Dr. Walshe, speaking of the different forms of valvular lesion, says that only one causes sudden death-aortic regurgitation, and that the more pure and uncomplicated it is, i.e., by dilatation and hypertrophy, the greater seems to be the danger of fatal syncope. He mentions eleven cases; no large nnmber considering hislong and extensive experience; and the only instance in which $I$ have known sudden death to be entirely attributable to valvular disease was one of aortic regurgitation. Its occurrence in these cases is explained by what $I$ have said of the tendency of this afiection to "stagnation" rather than "obstruction" in the circulation, and the liability of the former condition to cause syncope from deficient supply of blood to the nerrous centres. 'This erplanation applies especially to the cases which secmed to Dr. Walshe unaccountable, in which no hypertrophy or dilatation existed, the tendency to stagnation being, under these circumstances, uncom. pensated.

It may be stated then, and the conclusion has been fortified by the c.imination of post mortem records and reference to the experience of others, that, so far from life being apt to be cut short suddenly by syn. cope, sudden death is a contingency which may almost be left out of consideration in valvular discase, except in aortic regurgitation. I need scarcely refer to the unfarourable influcnce exerted by the dread of sudden dissolution, or to the relief which we can afford by removing this apprehension, which, spoken or unspoken, follows the sufferer who becomes aware that lie is the subject of heart-disease.

Pulnonary affections are the most common imme. diate cause of death, and pulmonary symptoms among the most common of the immediate precur. sors of this event. Dyspnoea, at first coming on only after exertion, is excited by slighter canses of most varied kinds, or sets in withont any assignable rea. son. The paroxysms are more severe and lasting. Frequently, it becomes habitual, and the patient is unable to lie down. This cardiac dyspnoen is pecu. liar, and readily distinguished from that of emphy. sema or asthma; it is rather want of breath than difticulty of breathing. The air enters and leaves the lungs freely, but does not satisfy the imperious demand which is felt, and which arises from the obstruction to the passage of blood through the langs. There is very commonly cough, with or without free expectoration, and the auscultatory phenomena may be of the most varied character. Ultimately therg will be the signs of bronchitis, effusion into the pleural cavity, or of pneumonia, or of combination of these, according as ono or other is to constitute the fatal complication. Bronchitis is not often the cause of death. Pleurisy, with effusion, or more frequently dropsical accumulation in the pleural cavity, is common. This last may be one of the manifestations of general dropsy, or strictly local and not associated with dronsical effusion elsewhere. Most common is congestive pneumonia in various degrees up to pulmonary apoplexy. This is most frequently a consequence of mitral affection, but is sonetimes met with in aortic disease. It may oocur independently of dropsy; but more often is associated with this condition, either as the final and fatal complication, when it has existed for a longer or shorter time, or the two coming on together.

Dropsy, which I have placed among the causes of death, would in most cases be more properly designated a precursor; associated pulmonary affections constituting the actual cause. It may come on very $\frac{\text { 의 }}{3}$ slowly, showing itself first as occasional slight $N$ œdena about the ankles; then permanently esta- $O$ blishing itself; gradually creeping up, reaching the $D$ knees, invading the thighs and abdomen; the breath all this time becoming shorter, the strength failing, $N$ and the symptoms increasing; till at length the pa. N tient reaches almost the climax of misery before $N$ death brings release from his sufferings. Or the course of the affection may be rapid, usually from $\infty$ the effect of pulmonary congestion or inflammation. As a prognostic sign, it is always of great, but by no means uniform, gravity. When it comes on? slowly in a patient who has enjoyed the advantages $\frac{T}{T}$ of repose, good diet, fresh air, etc., it may perhaps be kept down for a time; but once established it will $\overparen{Q}$ usually go on, in spite of treatment, slowly but $\frac{?}{\mathbb{D}}$ surely, to a fatal termination. It is a very serious 0 indication when it accompanies an attack of pul- 
monary congestion, or when it follows some debilitating influence; but in this case it is often recovered from. The probability of this favourable event in any given case will be estimated, according as the immediate exciting cause is inherent or accidentalin the state of the heart itself or the unfavourable conditions to which the patient may have been exposed. If the heart is found to be large and dilated, and the dropsy has crept on without provocation, or has been brought on along with pulmonary congestion by a little over-exertion or some other trivial circumstances, the chances are against recovery. If, on the other hand, the patient has been underfed, overworked, exposed to cold and wet, or has undergone other hardship, while the heart is not very notably enlarged, the probabilities are in his favour, if placed in favourable conditions. As a matter of personal experience, I am less anxious about a second attack of dropsy than about the first. To have recovered once is a reason for recovering again, provided always that the valvular lesion is not of the degenerative character.

Dropsy forms a very interesting question, and I am tempted to enter upon it a little more at length. It is generally, and I believe rightly, attributed to the obstruction, actual or virtual, of the circulation, caused by the cardiac disease. Opinions have fluctuated as to whether dilatation or the valvular lesion was the efficient cause. If my reasoning have been correct, the rôle of dilatation, as a cause of anything, is very small; its value as an indication remaining, however, as great as ever. But Dr. Walshe has raised the question whether heart-disease of any kind is of itself sufficient to give rise to dropsy, besing it upon the fact that dropsy is present in come cases of heart-disease, and absent in others apparently in all other respects similar.

$\mathrm{He}$ advances a series of propositions expressing facts derived from his experience, which may be summed up in the statement that any single valvular disease or combination of these, any structural alteration alone or complicating valvular affections, may exist for a considerable time without necessarily producing dropsy. He concludes from this that "something beyond and in addition to any one, or any group, is required in order to entail dropsy." It might with equal force be concluded that something beyond and in addition to mitral regurgitation and right hypertrophy is required to produce pulmonary apoplexy, since these conditions often coexist for years without giving rise to it.

But, to follow out Dr. Walshe's reasoning, he says again:" Some active cause beyond and independent of the beart is shown by the fact of no direct relation existing between the amount of heart-disease and dropsy; that dropsy sometimes comes on suddenly from extraneous causes, the state of the heart remaining, as far as is ascertainable, in precisely its previous condition; that dropsy comes and goes under treatment and spontaneously, while the organic changes in the heart are permanent and unmodified."

He does not, of course, ignore the influence of heart-disease, acknowledges that local conditions in the heart establish a difficulty in the circulation, but asks, "What influence actually and directly leads to the dropsical exosmosis?" replying that it is compound-in the blood, impoverishment-in the capillaries, a conceivable variation in density or texturein the tissues, innutrition. He believes also that not stagnation merely, but other and more effective agencies work out all these changes.

A sufficient reply might be given to all this in the words of Dr. Latham on the same subject: "There are several forms of unsoundness in the heart which may be sæid rather to tend towards a certain effect upon the circulation than necessarily to produce it. They must reach a certain amount before the effect is sure to follow. Yet when each separately would not be enough to produce it, from their combination it would arise inevitably."

Acknowledging the existence of this tendency to dropsy inherent in heart-disease, it is easily understood how a slight extraneous cause, a cold, overwork, temporary debility, etc., increasing the task on the heart or diminishing for the moment its power, may bring it on, and how on the removal of these exciting causes it may disappear, the organic condition remaining the same. The changes in the blood, capillaries, and tissues, in which Dr. Walshe finds the actual and direct cause, again, can only be regarded as tendencies co-operating with those contributed by the impeded circulation.

It further seems to me difficult to imagine more effective agencies in the production of the changes referred to than a delayed circulation. The sluggish stream can neither furnish the digestive secretions in due quantity and of proper quality, nor take up the nutritive materials with normal rapidity, nor can the assimilating organs, impeded in their function by chronic congestion, effect perfectly the further changes necessary to the formation of healthy blood. The tissues, also, permeated only by a slow current of unhealthy blood, can neither obtain sufficient matter for their renewal, nor get rid of the products of waste, and consequently fall into a state of degeneracy.

But there is another consideration to be taken into account in the causation of dropsy, which goes far to explain its occurrence in one case and not in another; viz., the varying degree of pressure to which the capillaries are exposed under different circumstances of "stagnation" or "obstruction". When a vein is tied or blocked in any way, the heart continues to drive blood along the arteries of the part, and there being thus obstruction in front and pressure from behind, the capillaries are exposed to a distending force which favours effusion and a local dropsy is quickly induced. But in valvular disease of the heart, the case is by no means so simple. Here impediment in front and want of propulsion from behind combine in varying proportions to render the circulation slow. The predominance of obstruction on the one hand, or of mere stagnation on the other, will obviously make a great difference in the tendency to dropsy; but it is extremely difficult to estimate the degree in which one or other exists in any given case.

It would seem, at first sight, that, in aortic disease, whether obstructive or regurgitant, so long as the mitral valve remained competent, there could only be "stagnation" from propulsion of an insufficient amount of blood into the systemic capillaries, and there can be no doubt that this is the primary tendency of these affections. The right heart and the pulmonary circulation are, however, also affected. If blood arrived in sufficient quantity in the right auricle, as the right ventricle has an equal capacity with the left and has no affection of the valves to interfere with its action, it would send into the lungs a larger quantity than the left sent into the system, a larger quantity, therefore, than it could receive from the lungs. There would, consequently, be accumulation of blood within the pulmonary vessels, and obstruction to the pulmonary circulation, limited only by the slowness of the supply from the systemic veins. Hypertrophy and dilatation modify the results. Hypertrophy will certainly tend to prevent stagnation when the valvular lesion is constrictive, and dilatation with hypertrophy will have the same. effect in regurgitation, the increased capacity of the 
ventricle making up for a return of a portion of the blood from the aorta.

Turning now to clinical observation as bearing upon this point, obstruction or stagnation in aortic valvular disease. It is in aortic regurgitation that fatal syncope is liable to occur, caused by failure in the supply of blood to the nervous centres, and explained by what has been said on the subject of stagnation. Pulmonary apoplexy is not so common in aortic as in mitral disease, but it is occasionally met with. In some instances, but not invariably, it may be due to secondary mitral regurgitation from dilatation. Dropsy is common as a termination of regurgitant disease, sometimes with phenomena strongly indicative of pulmonary and venous obstruction, but often with symptoms which show that there is no engorgement of the veins and capillaries, and that the exudation of serum is due simply to the sluggish motion of impoverished blood through the tissues without pressure on the vessels. The face is pale, and the surface generally bloodless, the tip of the nose livid and cold, the veins comparatively empty. Pulmonary symptoms are not prominent. The dropsy generally advances slowly, and in the absence of dangerous pulmonary complications, often reaches an extraordinary degree of development, finally proving fatal by passive accumulation in the peritoneum, pleuræ, or pericardium.

In mitral disease, congestive pneumonia is more common as a final complication; and the clinical history is more or less that of pulmonary congestion, secondary changes in the right side of the heart, and systemic venous engorgement-all characteristic of obstruction, as distinguished from stagnation. But the blood, finding its way into the left ventricle with difficulty, or regurgitating into the auricle, will be sent in diminished quantity into the aorta. Stagnation, therefore, enters into the case from deficient vis a tergo; but, as this arises secondarily from the obstruction cutting off the supply of blood, the latter will predominate. It is exceedingly difficult, however, during life, to estimate the degree of vascular pressure, unless dropsy is to be taken as an indication; and still more difficult to determine it by examination of the heart after death. I have already attempted to explain the conservative action of the secondary changes in the walls and cavities of the heart not due to weakness or degeneracy. I revert to it for a moment, only to say that, unless this be admitted, it seems to me impossible to understand how the circulation has been carried on at all in the state of valves often seen after death.

To return now to the application of the prognostic indications enumerated to cases of heart-disease, under the various circumstances mentioned in the early part of this paper. These indications we have found to be based upon the following considerations.

1. The organic condition of the heart, which will depend upon-

$a$. The valve affected; and the character, obstructive or regurgitant, of the lesion. This we learn by means of the murmurs. The order of relative gravity has been given, and the special dangers and tendencies of each pointed out.

$b$. The extent of the injury to the valve, and the degree of mechanical difficulty to which it has given rise. This, which is of far greater importance than merely ascertaining the seat of the lesion, is indicated by the structural changes in the walls and cavities of the heart, dilatation, and hypertrophy, and by

2. The degree of impairment in its functional efficiency, as shown by-

a. The evidence of derangement in the systemic and pulmonary circulation (habitual cardiac symptoms);

$b$. The liability to paroxysms of dyspnca, or attacks of palpitation, etc. ;

$c$. The existence of secondary consequences-pulmonary complications or dropsy.

3 . The state of general health and soundness, including-

$a$. The condition of the blood and tissues-the existence of anæmia and innutrition;

$b$. The soundness and functional activity of the important viscera, or the reverse.

4. The presence or absence of conditions tending to aggravate the valvular or structural lesions in the heart, or to precipitate the occurrence of complications; such as-

$a$. The progressive or stationary character of the disease in the valves;

$b$. The structural health or degeneracy of the walls of the heart and coats of the great vessels, when this can be ascertained;

c. The mode of life of the patient.

As has been said already, these considerations have very different weight in different stages; the last class of conditions, which may be called dynamic influences, being of the greatest importance early.

The case in which a valvular murmur exists, without either structural changes or symptoms, has already been considered. The lesion here being trifling, and the mechanical difficulty nil, the only point to be determined is, whether the lesion is likely to be increased, which may happen if the valves are subjected to severe and constant strain from the mode of life of the patient, or from acute or chronic rheumatism or gout; and will almost certainly be the case, if the disease is degenerative in character. The liability of aortic regurgitation occasionally to cause fatal syncope must not, however, be forgotten. That this occurs without hypertrophy or dilatation, we have on the authority of Dr. Walshe. Whether there may have been a complete absence of symptoms, I am unable to state.

When, with a valvular murmur, there is hypertrophy or dilatation, or both, but no symptoms of deranged circulation, the most important point to ascertain is still the character of the lesion, stationary or progressive. Next, perhaps, in importance, will be the dangers to which the patient is exposed, by his mode of life, of further damaging the valve on the one hand, or of inducing complications on the other. The structural changes, however, being present, and by their presence indicating a condition of valve strongly tending to the production of functional derangement, this derangement will sooner or later follow, but at what interval of time will be most uncertain. The patient may reach the period of life at which a general decay of the powers takes place, and the damaged organ will probably be the first to give evidence of this; or some debilitating cause may intervene, or some complication arise in the lungs from exposure to cold, etc. The probability of early failure of the heart's vigour, the liability to complications from slight external causes, and the danger attending these complications, will all be greater, the greater the alteration in the walls and cavities of the heart. In the absence of symptoms, unless there is reason to believe the valvular affection degenerative or otherwise progressive in character, a continued immunity may be expected, with greater or less confidence, according to the amount of structural change; this expectation being limited by any indication of failure in general health and vigour, and subject to accidental interruptions.

As symptoms manifest themselves, hypertrophy and dilatation cease to be the only measure of the 
valvular incompetence, which is more directly manifested by the evidences of deranged circulation in the lungs or system. These consequently are to be carefully inquired into. The pulse is to be examined chiefly with respect to the indications it gives of ample or insufficient supply of blood, the characteristic modification of the particular valvular affection present being always borne in mind. A comparison also should always be instituted between the strength of the pulse and the force of the heart's impulse. The state of the veins and capillaries will usually be evident, and is of the greatest importance. The eircumstances under which dyspncea is experienced, and the liability of the heart to palpitation, must be inquired into. The information thus obtained, considered in connexion with the existing valvular affection and the degree of dilatation and hypertrophy, will furnish grounds for an opinion as to the patient's actual condition. If the symptoms are not severe, he may long remain in statu quo, or may go downhill very gradually. His future prospects will depend greatly on the influences, favourable or otherwise, which may be in operation-on the state of his blood and tissues, on the pathological character of the valvular lesion, and on the external conditions to which he is exposed. The state of the blood and tissues will affect his immediate prospects : if he is anæmic and ill-nourished, unless these conditions can be remedied, more serious symptoms are imminent. The character of the valvular lesion will have a more remote bearing. The position and mode of life of the subject, whether he is poor, compelled to toil, and exposed to great variations of temperature, or is more happily situated, will obviously have a great influence, both immediate and remote.

When the symptoms become more grave, the degree in which they in themselves threaten life will first claim attention; and it will materially influence the prognosis, according as they are found to be due solely to the heart-disease, or are accounted for by exposure to unfarourable influences. The statical condition of the patient-the valve affected, the degree of dilatation and hypertrophy, the vigour of the heart's action, the state of the pulmonary and general circulation-will now be by far first in importance; the dynamic influences little operative. Taking now two patients, rich and poor, the balance will incline in favour of the poor man. For him, rest, good diet, treatment reversing the conditions which have accelerated the progress of the disease and preaipitated its consequences, may do much. There are no equally powerful remedial measures that we can bring to bear on the patient who has enjoyed, and not abused, the advantages attending the possession of wealth.

When consequences still more serious have arisen -pulmonary œdema, or congestion, or inflammation, or apoplexy, dropsy of the areolar tissue, or of the serous cavities of the abdomen and chest-now, indeed, it matters not greatly for the moment, whether the valvular disease has been rheumatic or degenerative in origin. The first point to be considered is the amount of mischief in the lungs, or the extent of the dropsy, and the rate of development of the one or the other; whether, again, any adequate external cause has cooperated in inducing them; next, the degree of dilatation and hypertrophy which, as indicating the preexisting mechanical difficulty and injurious tendency of the valvular lesion, give now more definite prognostications than the state of the pulse, the embarrassment of the respiration, etc., which are affected by the complications possibly accidental. Under these circumstances, the chances are altogether on the side of the poor man, and almost in proportion to the labour and privation to which he may have been exposed; the complications arising not solely from the state of the heart, but being due also to external influences; whereas, in the case of persons who have previously been sheltered from all injurious agencies, the only assignable cause is in the heart itself; and it is improbable that, having so far failed as to permit of these complications, it will be able to cope with the further difficulty to which they have given rise.

\section{ON THE EVACUANT AND ASTRINGENT PLANS OF TREATING CHOLERA.}

\section{By Haminton Kinglake, M.D., Taunton.}

OF the many diseases that rightly claim the attention of the physician, there is at the present time one which comes home to him with much anxiety, because of the uncertainty in the weapons at his disposal for resisting its invasion; and thus it is that, notwithstanding the light of past experience and the amount of intellectual energy that has been expended on the subject of cholera, we should at this moment be fiercely contesting the question whether the disease be best treated by one class of remedies or its exact opposite-i.e., by evacuants or astringents.

I have no intention, in giving expression to the views which this controversy has suggested, to join or do battle on either side; especially as I think that, in this as in most other contested questions, the truth is divided between the belligerents. All that I propose to do is this : to inquire, in as few words as possible, how far the evacuant and astringent modes of dealing with cholera are consistent with the indications of cure as they present themselves in the course of the disease; and to assign to each class of remedies its proper place in the order of treatment.

Before, however, entering on this inquiry, it is necessary to be armed with a hypothesis, in definition, as it were, of the choleraic poison; and as the one which makes it to consist of organised germs, capable, under favourable conditions, of rapid increase and development, in the fluid on which they may, have fastened, is in accord with the main facts in the history of the disease, there is every reason for accepting it until a nearer approach to the actual truth be attained.

From what we already know of the habits, so to speak, of the class of zymotic poisons to which that of cholera belongs, it would appear that the germs representing such poisons find their appropriate food, and therefore the main conditions of their activity and increase, in certain substances educed from organised matter in the course of its decomposition or conversion into more simple or binary compounds; so that, if the blood should happen to become unduly charged with such decomposing substances, either through its importing from without food, air, or water, in a tainted condition, or through any break in that after series of oxidations by which these, along with the effete tissue-products, are ultimately shorn of their organic character, the choleraic germs that might have existed in or subsequently obtained access to the blood so affected, would find there the condition ready at hand for perfecting their development: whereas, if the food, air, and water received into the system be free from taint, and the effete materials of the organism should follow their natural course of oxidation unin. terruptedly, and go straight to the excretory organs to be eliminated, the quantity of decomposing organic matter existing at any one time in the blood would be kept within the limits consistent with 